\title{
3D DOCUMENTATION AND BIM MODELING OF CULTURAL HERITAGE STRUCTURES USING UAVS: THE CASE OF THE FOINIKARIA CHURCH
}

\author{
K. Themistocleous ${ }^{\mathrm{a} *}$, A. Agapiou ${ }^{\mathrm{a}}$, D. Hadjimitsis ${ }^{\mathrm{a}}$ \\ ${ }^{a}$ Cyprus University of Technology, Department of Civil Engineering and Geomatics, 3036 Limassol, Cyprus - \\ \{k.themistocleous, a. agapiou, d.hadjimitsis\}@cut.ac.cy
}

KEY WORDS: 3D models, BIM, cultural heritage, documentation

\begin{abstract}
:
The documentation of architectural cultural heritage sites has traditionally been expensive and labor-intensive. New innovative technologies, such as Unmanned Aerial Vehicles (UAVs), provide an affordable, reliable and straightforward method of capturing cultural heritage sites, thereby providing a more efficient and sustainable approach to documentation of cultural heritage structures. In this study, hundreds of images of the Panagia Chryseleousa church in Foinikaria, Cyprus were taken using a UAV with an attached high resolution camera. The images were processed to generate an accurate digital 3D model by using Structure in Motion techniques. Building Information Model (BIM) was then used to generate drawings of the church. The methodology described in the paper provides an accurate, simple and cost-effective method of documenting cultural heritage sites and generating digital 3D models using novel techniques and innovative methods.
\end{abstract}

\section{INTRODUCTION}

UAVs have become a common tool in cultural heritage and archaeological research as they provide higher resolution images compared with satellite imagery. Research indicates that unmanned aerial vehicles (UAVs) can be used for low-altitude imaging and remote sensing of geospatial information (Colomina \& Molina, 2014; Cho et al., 2013; Mayr, 2013; Petrie, 2013). UAVs are being used for surveying cultural heritage sites due to their affordability, reliability and ease-ofuse (Themistocleous et al, 2015a; Themistocleous et al, 2015d, Lo Brutto et al., 2014; Rinaudo et al, 2012). Recent developments in photogrammetry technology provide a simple and cost-effective method of generating relatively accurate 3D models from 2D images (Ioannides et al, 2013; Themistocleous et al, 2015a; Themistocleous et al, 2015b; Themistocleous et al, 2014; Themistocleous et al, 2015c). These techniques provide a set of new tools for cultural heritage experts to capture, store, process, share, visualize and annotate 3D models in the field. According to Colomina and Molina (2014), the use of UAVs for surveying cultural heritage sites is becoming increasingly common, due to the ease of use and the quality of the processed measurements.

In this study, UAV images of an architectural cultural heritage site, the Church of Panagia Chryseleousa in Foinikaria, Cyprus, are used to create an accurate model of the church. Building Information Modeling (BIM) was used to document the church and also produce a 3D model and CAD drawings of the structure that will be used for future restoration and/or expansion works. The study found that using UAVs provides a relatively quick, non-invasive and cost-effective manner of documenting the church compared with traditional survey methods.

\section{STUDY AREA}

Foinikaria village is located in the Limassol District of Cyprus (figure 1).

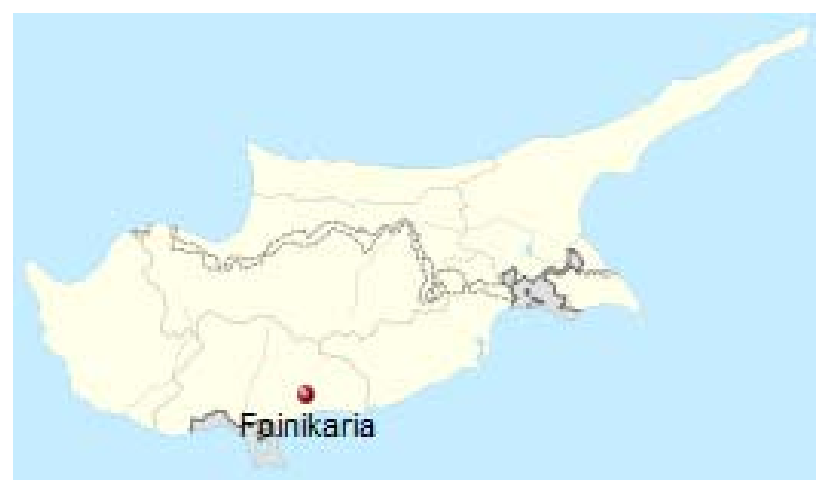

Figure 1. Foinikaria, Cyprus

Foinikaria has existed since the medieval times and possibly has its origins from the Byzantine period. The village includes the Church of Panagia Chryseleousa, which is a triple-aisled basilica bearing pointed vaults and covered with tiles (figure 2). The church was built with local stone in 1835 . The bell tower was incorporated on the junction located on the eastern angle of the south wall with the narthex. The south entrance of the church is covered by a roofed extension supported by pillars forming 4 arches. The entrances have elaborate carvings similar to the belfry. Religious symbols and shapes adorn the narthex and the rest of the edifice. The church is under the protection of the Antiquities Department of Cyprus. The survey was done in cooperation with the Holy Bishopric of Lemesos in an effort to document the church in a short amount of time. 


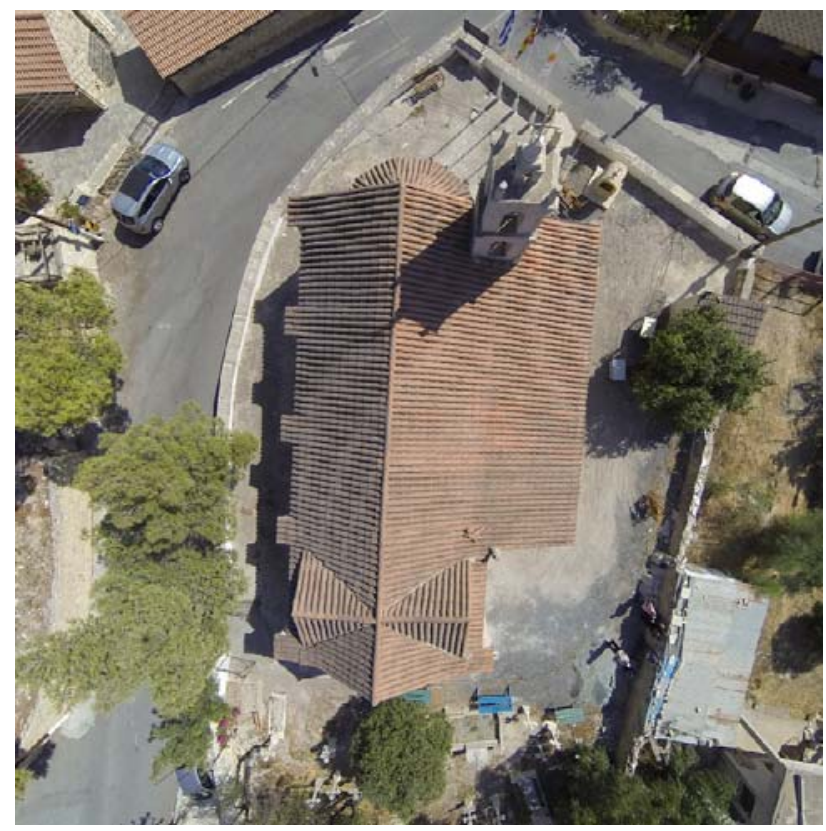

Figure 2. Foinikaria Church, aerial view

\section{METHODOLOGY}

In the study, a hexacopter with a compact camera was used to conduct the aerial 3-D survey of the Foinikaria Church. Over 1,000 images were taken within 1 hour, which were later postprocessed using Agisoft Photoscan Professional to create a 3D model. The 3D model was then exported and the BIM model was created in order to produce the drawings required. Such a methodology (figure 3) provides archaeologists and cultural heritage experts a simple and cost-effective method to document and generate relatively accurate 3D models and drawings from 2D images of cultural heritage sites.

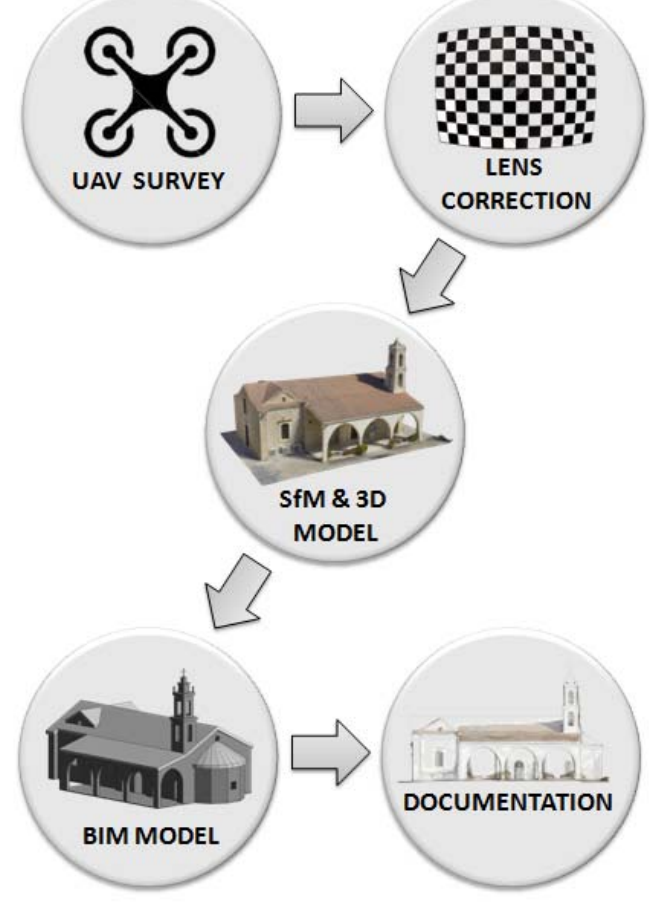

Figure 3. Methodology

\subsection{UAV}

The DJI F550 hexacopter with attached GoPro HERO+ 12MP camera was used to take images of the church (figure 4). The hexacopter was used due to its maneuverability to take images above and around the church. A gimble was added to the camera to provide high precision 3-axis camera stabilization system that allows for smooth aerial photography. The integrated GPS system included position holding, altitude lock and stable hovering to provide constant stability in flight. The flying altitude was relatively low at 10 meters in order to produce higher resolution images.

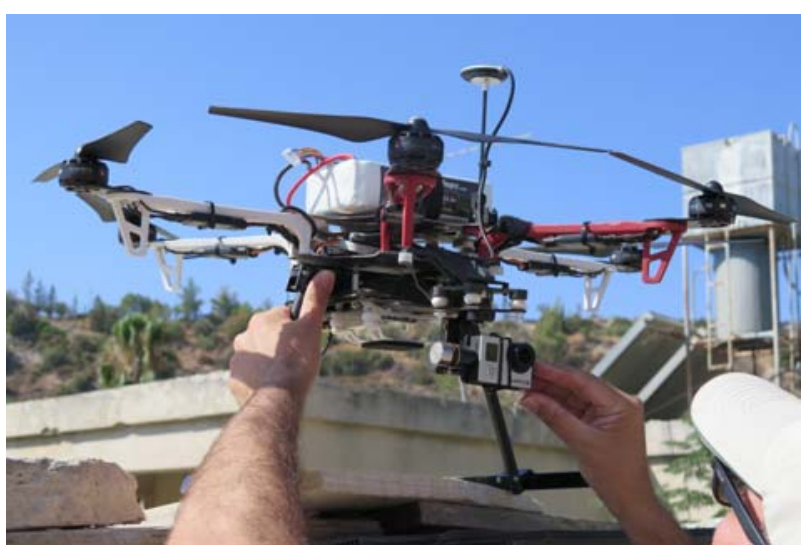

Figure 4. F550 hexacopter with attached GoPro camera

The copter was flown in manual mode to ensure that all the images necessary for image processing are taken and to avoid any obstacles around the church, especially trees (figure 5). During the flight, two operators were required for the aerial survey; one operator controlled the flight path of the UAV while the other operator monitored the UAV telemetry data. The telemetry information was transmitted to the operator on a monitor in order to verify the position, distance, height and battery life of the hexacopter.

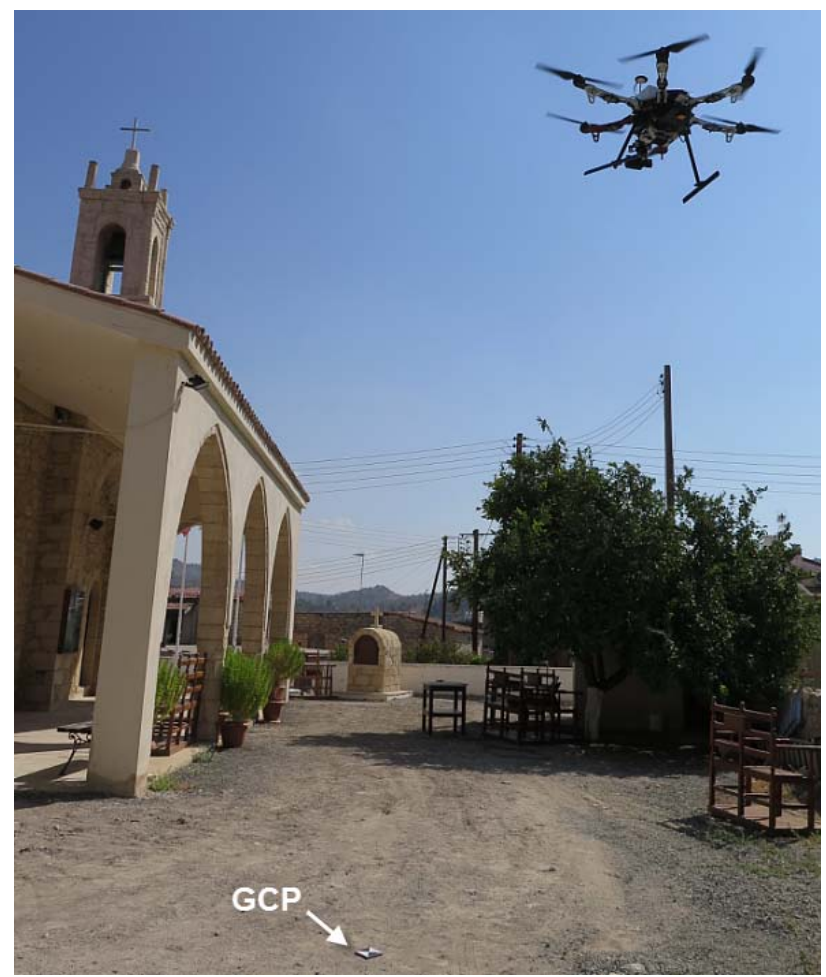

Figure 5. UAV flying over Foinikaria church 


\subsection{Image processing}

Since the GoPro HERO3+ camera has a wide-angle lens, lens distortion removal was required by calibrating the camera and removing the distortion by estimating the camera calibration parameters of center principal point, square pixels and distortion models using the Brown distortion model (Brown, 1966). Camera calibration data can also be calculated by the Agisoft Lens software (and exported if needed) or imported from an external source.

Agisoft PhotoScan Pro photogrammetry software was used to conduct the image processing. Agisoft PhotoScan is capable of interpolating digital images in order to create high resolution, scaled and georeferenced 3-D models from them. All clear images with sufficient overlap were included in the processing in order to generate a dense point cloud of the church. Ground Control Points (GCP) were applied to correct the scale and georeference the model. To complete the georeferencing task, the program requires either Global Positioning System (GPS) coordinates associated with cameras, provided in an EXIF/ plain text file or GCP coordinates that can be used to achieve higher accuracy (up to $1 \mathrm{~cm}$ ). Based on the latest multi-view 3D reconstruction technology, the software operates with arbitrary images and is efficient in both controlled and uncontrolled conditions (Remondino et al, 2011). Photos can be taken from any position, providing that the object to be reconstructed is visible on at least two photos with sufficient overlay. Both image alignment and $3 \mathrm{D}$ model reconstruction are fully automated.

Agisoft PhotoScan generates the building of 3D models by reconstructing a dense point cloud and generating polygonal mesh model based on the dense cloud data. In addition, the software has an automatic tool of texture projection, which makes automatic projection from the color directly on the surfaces possible (Meszaros, 2011). The first step in the program's procedure is called Structure from Motion (SfM). The software analyses the dataset, detecting geometrical patterns in order to reconstruct the virtual positions of the cameras that were used, align the images, including building a sparse point cloud (tie points). The software automatically aligns images based on pairing of features (e.g. sand grains of different colors, etc.) and creates a "sparse cloud" of elevations based on these points. The completed alignment is then used to develop a dense point cloud which uses it to create a surface which allows draping of the imagery over the model by creating and building a texture from the original images and overlays the imagery onto the model mesh (Themistocleous et al, 2014). The software then builds a polygon mesh and calculates a texture for the mesh.

Agisoft PhotoScan Professional supports a range of input formats including JPEG, TIFF, PNG. A wide range of output formats (GeoTiff, xyz, Google KML, Wavefront OBJ, VRML, COLLADA, PDF) ensures easy import to any GIS system for future photogrammetric analysis (Themistocleous et al, 2014).

After the 3D model generation, the point cloud model was converted to the rcp indexed format and imported into Autodesk Revit software to generate a Building Information Model (BIM). BIM is an intelligent 3D model-based process that involves the generation and management of digital representations of physical and functional characteristics of places. It can be defined as a BIM virtual information model. BIM design tools allow extraction of different views from a building model for drawing production and other uses. After the BIM model was constructed, drawings of the plans, elevations and sections of the church can be generated directly from the BIM model for documentation purposes. Also, information such as material, color, height, thickness, etc. can be added to each component in the BIM database.

\section{RESULTS}

Over 1,000 images were taken at the Foinikaria Church, which were post-processed by removing the lens distortion and then processed using the Agisoft Photoscan Professional software. The processing began with the ortho-mosaic production from these multiple images, which was used for the 3D model. As shown in figure 5, 32 GCPs were used, which were distributed equally around the church using the WGS84 coordinate system taken with a centimetre accuracy GPS. The ground resolution was $3 \mathrm{~mm} /$ pixel. Following the ortho-mosaic production, the model was exported from Agisoft into SketchFab (https://sketchfab.com) for visualization purposes (figure 6). The study found that particular areas were not well documented on the 3D model, due to an insufficient number of images in specific locations, such as the bell-tower. This is evident in Figure 6, where the bell-tower is not clearly modeled.

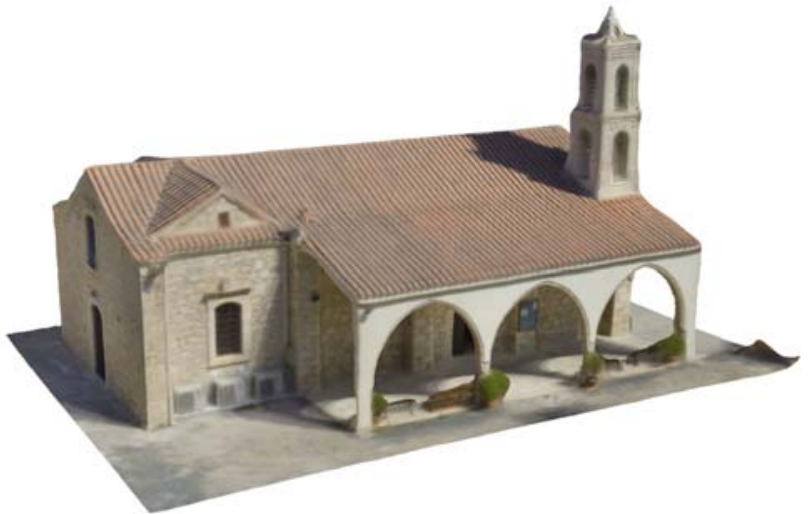

Figure 6. 3D model of the church

Autodesk Revit software was used to generate a BIM 3D model of the church, including the bell tower (figure 7). Figure 8 features the completed bell tower, where the BIM model is overlaid with the point cloud.

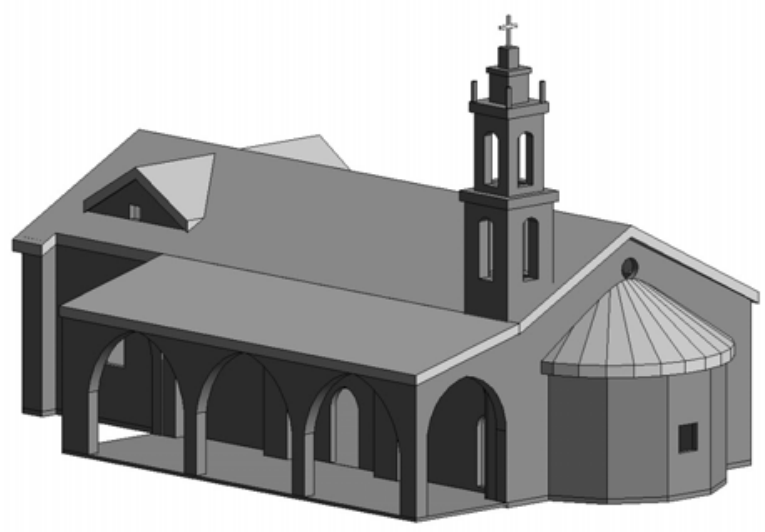

Figure 7. BIM model of the church

The point cloud provided enough information so the structure of the building can be accurately modeled without the need of any in-situ measurements. The point cloud information was especially necessary to model the roof, bell tower, arches and openings. This provided a fast and accurate method for documenting the church. As well, architectural cultural heritage buildings have a rough surface texture as a result of weathering; the point cloud was able to capture such details. 


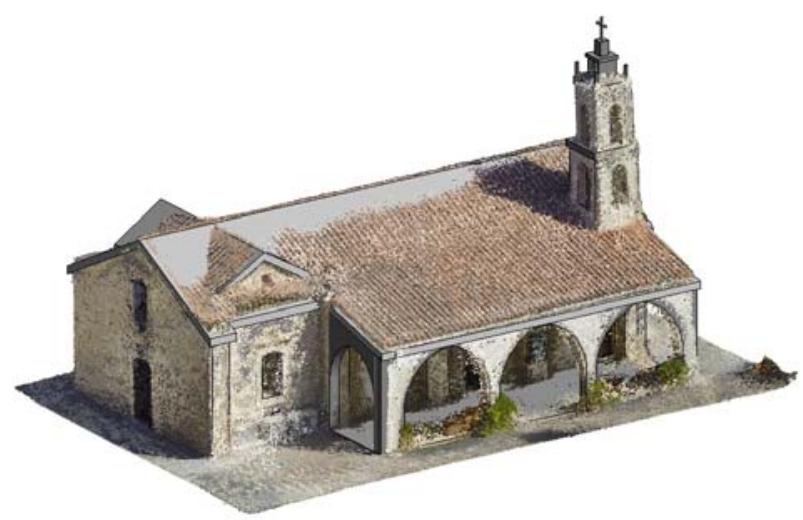

Figure 8. Point cloud with BIM model

Sections of the 3D model overlaid with the point cloud are evident in figure 9. This provides detailed information regarding the exterior walls of the church and the structure of the narthex.

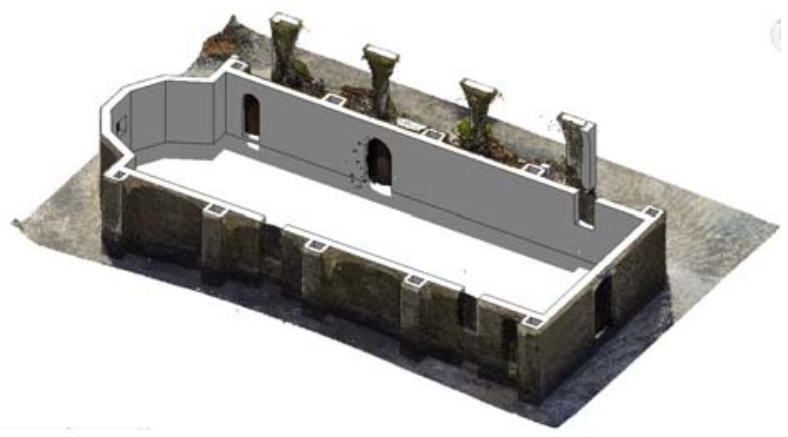

Figure 9. Point cloud section with BIM model

Using the Revit software, drawings including floor plans, elevations and sections of the church were generated (figure 10 and 11). A database was created to include information regarding the structure, including wall height, thickness, material, etc. This provided a valuable source of documentation of the church, for future restoration and maintenance works. Also, the documentation of the site was important to study possible expansion projects.
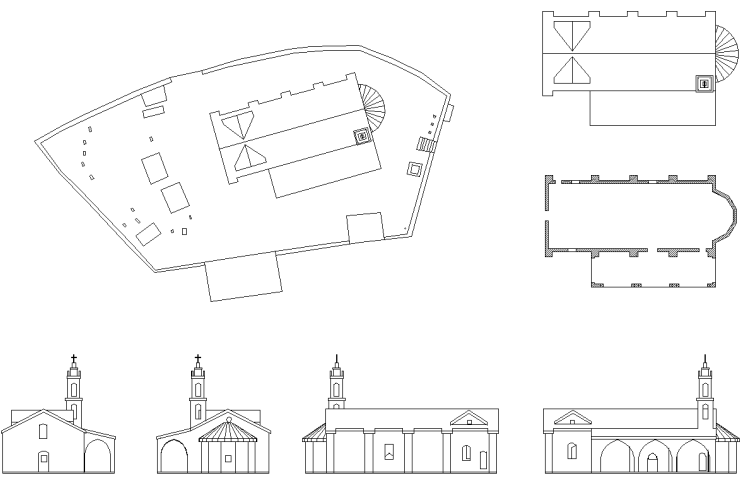

Figure 10. Drawings of the church generated from BIM

The elevations are also overlaid with the point cloud to provide additional information on the building, such as surface texture, color and materials (figure 11).
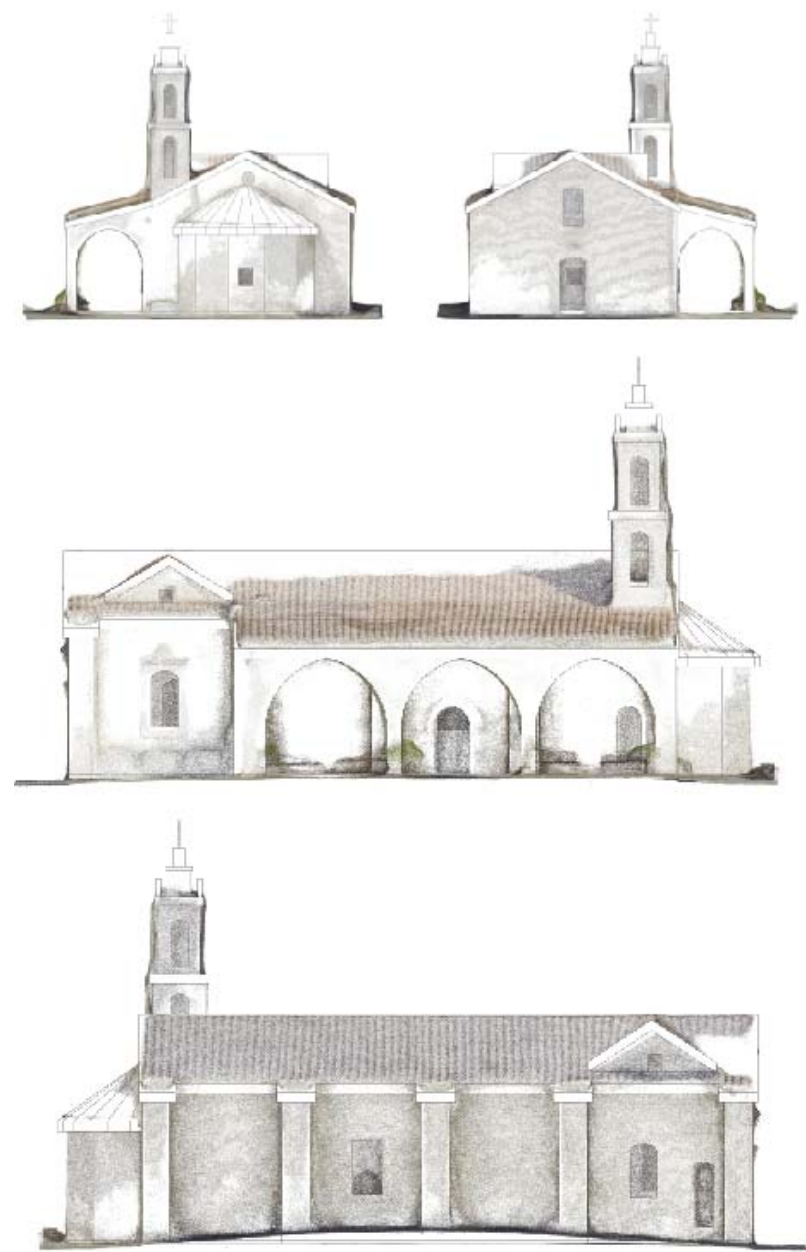

Figure 11. Drawings of elevations of the Foinikaria church

\section{CONCLUSIONS}

UAVs are becoming an extremely important tool for cultural heritage specialists to document and analyse cultural heritage sites and structures as they provide a cost-effective and efficient manner to acquire high spatial resolution data and generate reliable documentation in a timely manner. The study highlighted the ability of UAVs to provide high resolution data of a cultural heritage site using a non-invasive technology and high accuracy with the use of ground control points.

In this paper, the DJI F550 hexacopter with GoPro HERO3+ camera was used to survey the Foinikaria Church in high resolution. The aerial imagery obtained from the UAVs was imported into Structure in Motion software to create rapid and automated generation of a point cloud model and 3D mesh model. The point cloud generated was then exported in to BIM, in order to produce a BIM model and drawings of the church. The high accuracy documentation generated from the BIM model can be used for future renovation or expansion of the site.

\section{ACKNOWLEDGEMENTS}

Special thanks to the Holy Bishopric of Lemesos, Dn Spyridon Papavasileiou, the "ATHENA" project H2020-TWINN2015 of the European Commission, grant agreement No 691936 and the 
Eratosthenes Research Center RS lab of the Cyprus University of Technology.

\section{REFERENCES}

Brown, D. C., 1966. Decentering distortion of lenses, Photometric Engineering, 32(3), pp. 444-462.

Colomina, I. \& Molina, P., 2014. Unmanned aerial systems for photogrammetry and remote sensing: a review. ISPRS Journal of Photogrammetry and Remote Sensing, 92, pp.79-97.

Cho, G., Hildebrand, A., Claussen, J. Cosyn, P. \& Morris, S., 2013. Pilotless aerial vehicle systems: size, scale and functions. Coordinates, 9, pp. 8-16.

Ioannides, M., Hadjiprocopis, A., Doulamis, N., Doulamis, A., Protopapadakis, E., Makantasis, K., Santos, P., Fellner, D., Stork, A., Balet, O., Julien, M., Weinlinger, G., Johnson, P., Klein, M. \& Fritsch, D., 2013. Online 4D Reconstruction using Multi-Images available under Open Access. ISPRS Annals of Photogrammetry, Remote Sensing and Spatial Information Sciences, Volume II-5/W1, 2013, pp.169-174.

Lo Brutto, M., Garraffa, A., Meli, P., 2014. UAV Platforms for Cultural Heritage Survey: First Results. ISPRS Annals of Photogrammetry, Remote Sensing and Spatial Information Sciences, Volume II-5, 2014, pp.227-234.

Mayr, W., 2013. Unmanned aerial systems -for the rest of us. Proceedings of the 53rd Photogrammetric Week. Institute fur Photo-grammetrie, Universitat Stuttgart, pp. 125-134.

Meszaros, J., 2011. Aerial surveying UAV based on opensource hardware and software. Proceedings of the International Archives of the Photogrammetry, Remote Sensing and Spatial Information Sciences, XXXVIII-1/C22.

Petrie, G., 2013. Commercial operation of lightweight UAVs for aerial imaging and mapping. GEOInformatics, 16, pp. 2839.

Remondino, F., Barazzetti, L., Nex, F., Caioni, M. \& Sarazi, D., 2011. UAV photogrammetry for mapping and 3D modellingcurrent status and future perspectives. Proceedings of the Interna-tional Archives of the Photogrammetry, Remote Sensing and Spatial Information Sciences, pp. 25-31.

Rinaudo, F., Chiabrando, F., Lingua, A. \& Span, A., 2012. Archaelogical site monitoring: UAV photogrammetry can be an answer. Proceedings of the International Archives of the Photogrammetry, Remote Sensing and Spatial Information Sciences Volume XXXIX-B5, 2012XXII ISPRS Congress, 25 August-01 September 2012, Melbourne, Australia, pp. 583588.

Themistocleous, K., Agapiou, A., King, H.M., King, N. \& Hadjimitsis, D.G. , 2014. More Than a Flight: The Extensive Contributions of UAV Flights to Archaeological Research - The Case Study of Curium Site in Cyprus. Proceedings of the Progress in Cultural Heritage: Documentation, Preservation, and Protection. $5^{\text {th }}$ International Conference, EuroMed 2014, Limassol, Cyprus. Springer LNCS 8740, EuroMed2014 Conference, pp. 396-409.
Themistocleous K., Agapiou A., Cuca, B. and Hadjimitsis, D.G., 2015a. Unmanned Aerial Systems And Spectroscopy For Remote Sensing Applications In Archaeology. Proceedings of the 36th International Symposium on Remote Sensing of Environment (ISRSE-36), 11-15 May, 2015, Berlin Germany.

Themistocleous K., Ioannides M., Agapiou A., Hadjimitsis D.G. 2015b. A New Approach for Documenting Architectural Cultural Heritage: The Case Study Of Asinou Church In Cyprus, Proceedings of the International Conference on Sustainability in Architecture and Cultural Heritage, 11-12 December, Limassol, Cyprus.

Themistocleous K., Agapiou A., Lysandrou, V. \& Hadjimitsis, D.G., 2015c. The Use of UAVs for Remote Sensing Applications: Case Studies In Cyprus. Proceedings of the SPIE Remote Sensing Conference, 21-24 September, 2015, Toulouse, France.

Themistocleous, K., Ioannides, M., Agapiou, A. \& Hadjimitsis, D.G., 2015d. The Methodology Of Documenting Cultural Heritage Sites Using Photogrammetry, UAV And 3D Printing Techniques: The Case Study Of Asinou Church In Cyprus. Proceedings of the Third Interna-tional Conference on Remote Sensing and Geoinformation of Environment, 2015, 16-19 March, 2015. 